\title{
Family Presence During Resuscitation: Validation of the Risk-Benefit and Self-Confidence Scales for Student Nurses
}

Isabelle Bray (BSc(Hons) MSc PhD), Senior Lecturer in Public Health, Department of Health and Social Sciences, University of the West of England, Frenchay Campus, Coldharbour Lane, Bristol BS16 1QY

Gerard Kenny (BA(Hons), RGN, RN(Child), PhD), Independent Researcher

David Pontin (BSc MSc PhD RN RSCPHN), Aneurin Bevan Chair of Community Health, Faculty of Life Sciences and Education, University of South Wales, Pontypridd CF37 1DL

Rachel Williams, (RN) Senior Lecturer in Adult Nursing, Department of Nursing and Midwifery, University of the West of England, Glenside Campus, Blackberry Hill, Bristol BS16 1DD

John Albarran (RN, BSc(Hons) MSc, DPhil), Associate Professor in Critical and Cardiovascular Nursing, Centre for Health and Clinical Research, University of the West of England, Glenside Campus, Blackberry Hill, Bristol BS16 1DD 


\section{Abstract}

Background. There is increasing debate about the advantages and disadvantages of familywitnessed resuscitation. Research about the views of healthcare providers depends upon reliable tools to measure their perceptions. Two tools have been developed for use with nurses (26-item cost-benefit tool, 17-item self-confidence tool). Objectives. Firstly, to validate these tools for use with student nurses in the UK. Secondly, to report on the perceived risks and benefits reported by student nurses, and their self-confidence in dealing with this situation. Methods. A sample of 79 student nurses were invited to complete the tools. Itemtotal correlations and Cronbach's $\alpha$ were used to determine internal consistency. Factor analysis was computed to assess construct validity. The correlation between the two scales was explored. Results. 69 students completed a questionnaire. Very few had experience of family-witnessed resuscitation. Mean total scores were 3.16 (standard deviation 0.37; range 2.04-4.12) on the risk-benefit scale and 3.14 (standard deviation 0.66; range 1.94-4.82) on the self-confidence scale. Four of the original items were removed from the risk-benefit scale (Cronbach's $\alpha 0.86 ; 95 \%$ confidence interval $\geq 0.82$ ). None were removed from the selfconfidence scale (Cronbach's $\alpha 0.93 ; 95 \%$ confidence interval $\geq 0.91$ ). There was a significant correlation between the two scales $(r=0.37, p=0.002)$. Conclusions. There is first evidence that these tools are valid and reliable for measuring student nurses' perceptions about familywitnessed resuscitation. 


\section{Keywords}

Family-witnessed resuscitation; Student nurses attitudes; Instrument Validation; Risks and Benefit scale; Self-confidence scale

\section{Introduction}

There is increasing debate about the advantages and disadvantages of family-witnessed resuscitation, from the point of view of the patient, the family and healthcare providers. The presence of family members brings key benefits for the family that include greater acceptance that everything was done for their relative, contributing positively to the grieving process (Meyers et al., 1998, 2000, Doyle et al., 1987). International research with patients and families reveals a preference for close relatives to be invited to be present at resuscitation (McMahon-Parkes et al., 2009; Salmond et al., 2014; Weslien et al., 2006). Some health professionals, however, are concerned that the presence of family members may impact negatively on the resuscitation attempt, and may expose them to criticism and litigation (Mortelmans 2010). The gradual shift in healthcare culture towards acceptance of familywitnessed resuscitation as a right of both patients and their families (Walker, 1999, Fullbrook et al., 2007; McLaughlin et al., 2013) calls into question the ability of professionals to encourage and manage the presence of family members during resuscitation. It has 
implications for the training of doctors, nurses and other professions. Measuring the skills and readiness of healthcare providers to support family members through family-witnessed resuscitation is challenging, but is crucial to inform the development of policies and training around family-witnessed resuscitation in hospitals. Twibell et al. (2008) developed two tools to assess nurses' perceptions of family witnessed resuscitation and their confidence in managing it. In a sample of nurses in a teaching hospital in the United States it was found that nurses' perceptions of benefits, risks and self-confidence were strongly correlated $(r=0.56, p<0.001)$. Nurses who invited family presence during resuscitation were significantly more self-confident in managing it and perceived more benefits and fewer risks. The authors suggested that the generalisability of the tools should be assessed by testing them in other settings.

A replication study was performed by Chapman et al. (2013) who used the RB and SC scales among a sample of nurses and doctors $(\mathrm{N}=114)$ in an Australian non-teaching hospital. There was a positive correlation between the two scales $(r=0.46 ; p<0.001)$.

More recent work has used these scales to examine nurses' attitudes towards familywitnessed resuscitation in different speciality areas, both within the intensive care environment (Carrol, 2014) and across the hospital (Tudor et al., 2014). The tools have also been used to assess the effectiveness of educational interventions to increase student nurses knowledge, perception and confidence in facilitated family-witnessed resuscitation (Kantrowitz-Gordon, 2013; Powers, 2014). 
These studies have established, along with other work (Chapman et al., 2012; Güneş and Zaybak, 2009; Köberich et al., 2010), that practitioners with more experience with familywitnessed resuscitation are more likely to feel confident about managing family-witnessed resuscitation, and are more likely to invite family-witnessed resuscitation. An important educational question is whether practitioners with less experience can be educated to increase their confidence in performing resuscitation in the presence of family members, and their awareness of the potential benefits for patients and families. In order to assess this, it is first necessary to develop the RB and SC tools for use with less experienced practitioners. This study is the first step towards this goal. We have tested the original RB and SC scales with a group of nurses in the second year of their training at the University of the West of England, UK. The primary aim was to validate the tools in this population, which differs considerably from the previous two study populations in terms of geography, setting (educational rather practice-based) and level of experience. A secondary aim was to compare the overall results of the scales with those reported by previous studies.

\section{Methodology}

\section{Design}

This is a replication and validation study. The purpose of this study is to replicate the original study of Twibell et al. (2008) and validate the original RB and SC tools in a sample of student nurses in the UK. Comparisons can then be made with similar studies in the literature. 
Sample

The sample comprised a cohort of 79 second year nursing students from two education sites (Bristol and Gloucester). There were no exclusion criteria. All students attending that day were asked to consent, if they had not already done so, and to complete the questionnaire before taking part in the resuscitation simulation.

\section{Instruments}

The original 'Family Presence' tools developed by Twibell et al. (2008) were used, with the authors permission. The RB scale assesses nurses' perceptions of the risks and benefits of family presence during resuscitation. The SC scale assesses nurses' perceptions of their own self-confidence in managing family presence during resuscitation. The tools were developed based on the theories of Rogers (1995) and Bandura (1986), qualitative data from content experts, and the findings of earlier research (e.g. Sacchetti et al., 1996; Hanson \& Strawser, 1992; MacLean et al., 2003). Items were developed on the basis of the literature and interviews with expert nurses from a variety of clinical settings. Content validity was assessed by clinical experts in family presence, academics and statistical experts in design and testing. Following piloting, the final RB tool consisted of 26 items, and the SC tool comprised 17 items, each with a likert response ranging from 1 (strongly disagree/not at all confident) to 5 (strongly agree/very confident). The total score for each scale, obtained by summing the likert responses to the individual questions, ranged from 26 to 130 for the RB tool and from 17 to 85 for the SC tool. Mean total scores were calculated by dividing by the number of items. 
The tools were developed and validated on a sample of predominantly white, experienced nurses $(\mathrm{N}=375)$ practising in a teaching hospital in the United States and in a range of units (critical and non-critical care). The study demonstrated the reliability and construct validity of both scales. Twibell et al. (2008) reported that factor analysis of the RB scale confirmed a single interpretable factor which explained $53 \%$ of the variance in nurses' perceptions of risks and benefits of family presence. Four items were deleted due to low item-total correlations. For the SC scale, a single factor explained $52 \%$ of the variance in nurses' self-confidence to manage family presence, and no items were deleted. Cronbach's $\alpha$ was used to assess reliability, and was 0.96 for the reduced RB scale and 0.95 for the SC scale. No discrete subscales were identified.

The replication study by Chapman et al. (2013) was also carried out in a hospital that had no written policy on family-witnessed resuscitation. There were however some differences in that this was a non-teaching hospital so it is likely to have had a less severe case-mix than that the hospital in which the tools were developed, and the tool was validated amongst doctors as well as nurses. The authors concluded that their findings supported the validity and internal consistency of the RB and SC scales as measures to evaluate health professionals' perceptions of their self-confidence with, and the risks and benefits of, family witnessed resuscitation. Chapman et al. (2013) reported that after removal of six of the original 26 items in the RB scale, a single factor explained $52 \%$ of the variance in scores on this scale, and after removal of 
one of the original SC items, a single factor explained $62 \%$ of the variance in scores. Cronbach's $\alpha$ was 0.81 for the reduced RB scale and 0.96 for the reduced SC scale.

In the current study, demographic information (age, gender, ethnicity) was not collected due to the homogenous nature of the cohort (predominantly white females of school-leaving age). Additional questions were included (following Twibell et al., 2008) to gather data on the type of unit usually worked on in training (emergency department/critical care unit/non-critical care inpatient unit/outpatient unit/other) and how many times the respondent had invited a family member to be present during a resuscitation event (never/less than five time/more than five times). Students were also asked who they felt should make the decision about family presence during resuscitation efforts (patient/nurse/physician/family/other).

\section{Statistical Analysis}

Statistical analysis was carried out using Stata 12 (StataCorp, 2011). The distribution of responses to each item was tabulated. Negatively worded items were then reverse scored. Item-total correlations and Cronbach's $\alpha$ were used to determine internal consistency. A onesided 95\% confidence interval for Cronbach's $\alpha$ was calculated (Bleda and Tobias, 2000). Itemtotal correlations less than 0.2 indicated that the item should be dropped from the scale (Everitt, 2002). The adequacy of the Cronbach's $\alpha$ coefficients was assessed with reference to the matrix provided by Ponterotto and Ruckdeschel (2007). Total scores were computed 
separately for the RB and SC scales, by calculating the mean score for each participant (where participants had not responded to all items in the scale, the mean across all available items was calculated rather than excluding data for that participant, in order to maximise the sample size). The Normality of the scores were assessed visually and using the Shapiro-Wilk test. Responses to each scale were summarised by mean and range.

Following the methods of the original study (Twibell et al., 2008) and the replication study by Chapman et al. (2013), principal components factor analysis with varimax rotation was computed to assess structural validity. The Kaiser-Meyer-Olkin measure of sampling adequacy and Bartlett's test of sphericity were used to assess the appropriateness of a factor analysis.

The factor analysis for each scale excluded data from participants who did not complete all the questions in that scale. Scree plots were used to determine the appropriate number of factors for each scale.

To examine the evidence for a relationship between student nurses' perceptions of risks, benefits, and self-confidence related to family presence, during resuscitation, the Pearson correlation coefficient between the two scales was calculated. The coefficient is interpreted on a scale between -1 (perfect negative correlation) and +1 (perfect positive correlation). The associated $\mathrm{p}$-value gives the probability that the observed correlation is due to chance. 
Ethics

The study was approved by the Research Ethics Committee of the Faculty of Health and Applied Sciences at the University of the West of England. The purpose of the study was explained to the students in advance by a member of the study team and Participant Information Sheets and consent forms distributed. Students were informed that participation was voluntary and would not affect the students opportunity to take part in the planned resuscitation simulation training. They were also informed that the questionnaires were anonymous, so that the individual students could not be identified by their responses.

\section{Results}

Response rates

Sixty-nine completed questionnaires were received. This equates to a response rate of $87 \%$ of all students in the target cohort. Response rates to individual questions are tabulated in Tables 1 (RB scale) and 2 (SC scale). They ranged from 59/69 (86\%) to 69/69 (100\%) for the RB scale and from $61 / 69(88 \%)$ to $69 / 69(100 \%)$ for the SC scale. Of the 26 questions in the RB scale, 16 (62\%) were completed by all 69 respondents. The corresponding figure for the SC scale was 4/17 (24\%). Fifty-three (77\%) of respondents answered all 26 questions in the RB scale, and 59 (86\%) of respondents answered all 17 questions in the SC scale. 
Characteristics of the sample

Of the 55 respondents who answered the question about the type of unit they usually work on, responses were Emergency Department: 1 (2\%), Critical Care Unit: 5 (9\%), Non-Critical Care Inpatient Unit: 14 (25\%) and 35 (67\%) reported that they usually worked on another type of unit.

Experiences of and attitudes towards family witnessed resuscitation

The vast majority $(62 / 65=95 \%)$ of respondents had never invited a family member to be present during a resuscitation attempt. Nevertheless, $52 \%$ of the sample agreed that all families should have the right to be present at resuscitation, and $68 \%$ agreed that all patients have the right to have their families present.

When asked who should contribute to the decision about family presence during a resuscitation, the most unanimous response was for the patient (beforehand), with $98 \%$ of respondents agreeing they should make this decision, followed by the family ( $81 \%$ of responses), then the physician (76\%), with only $69 \%$ of respondents saying that the nurse should make this decision. When asked who was the best placed to make this decision, $69 \%$ felt this was the patient (beforehand), 19\% said the family, and very few opted for the physician or the nurse ( $5 \%$ and $7 \%$ respectively). 


\section{Scores on study variables}

The distribution of responses to each item are shown in Tables 1 (RB scale) and 2 (SC scale). There was no evidence of any floor or ceiling effects. Mean total scores were 3.16 (standard deviation 0.37 ; range $2.04-4.12$ ) on the RB scale and 3.14 (standard deviation 0.66 ; range 1.944.82) on the SC scale (the potential range for the mean total scores was 1.00 to 5.00 ). Although average scores were similar on the two scales, there was greater variability in the responses to questions about self-confidence. Based on Shapiro-Wilk tests there was no evidence of nonnormality (RB scale $p=0.09, \mathrm{SC}$ scale $\mathrm{p}=0.28$ ), therefore parametric methods were used in the analysis.

Scale evaluation

Item-total correlations suggested that some of the questions in the RB scale were discriminating less well (item-test correlation $<0.2$ for questions $4,7,8,10$ ), so these questions were removed from the scale. All the items in the SC scale were found to offer very good discrimination (item-test correlation 0.53-0.81).

Scree plots of both scales showed a clear drop in the proportion of variance explained for any more than one factor in both cases, confirming the one-factor solution reported in the initial testing (Twibell et al. , 2008) and replication (Chapman et al., 2013) of these tools. The results of the Kaiser-Meyer-Olkin measure of sampling adequacy $\left(\chi_{231}^{2}=636.5, p=0.000\right.$ for RB scale; 
$\chi_{136}^{2}=655.3, p=0.000$ for SC scale) and Bartlett's test of sphericity ( 0.668 for RB scale; 0.855 for SC scale) confirmed that a factor analysis of the data was appropriate for both scales.

A single factor solution explained $31 \%$ of the variance in the students' perceptions of risks and benefits of family presence. Factor loadings ranged from 0.21 to 0.82 (Table 1 ). The Cronbach's $\alpha$ reliability of the 22 -item scale was 0.86 (one-sided $95 \%$ confidence interval $\geq 0.82$ ). All 17 items on the SC scale correlated with the total score and were retained. A single factor solution explained $49 \%$ of the variance in the students' self-confidence with family presence at resuscitation. Factor loadings ranged from 0.45 to 0.83 (Table 2). The Cronbach's $\alpha$ reliability of the 17 -item scale was 0.93 (one-sided $95 \%$ confidence interval $\geq 0.91$ ). According to the reliability matrix for assessing the adequacy of internal consistency coefficients in light of sample size and the number of items per scale (Ponterotto and Ruckdeschel, 2007), the Cronbach's $\alpha$ values presented here for both the RB and the SC scale are rated as 'Excellent'.

\section{Relationships among perceptions}

The Pearson $r$ correlation between student nurses perceptions of the risks and benefits of family-witnessed resuscitation (RB scale) and of their self-confidence to manage familywitnessed resuscitation ( $S C$ scale) was significant $(r=0.37, p=0.002)$. In other words, confidence in dealing with family-witnessed resuscitation was associated with more perceived benefits and less perceived harms. 


\section{Discussion}

In this study we have validated the use of the family presence RB and SC scales, developed by Twibell et al. (2008) for use with nurses in the United States, on a group of student nurses in the United Kingdom. Our analysis has confirmed the one-factor solution for both scales as reported by Twibell et al. (2008) and Chapman et al. (2013). Four items were removed from the RB scale due to low item-total correlations, and there was some overlap with the questions removed in previous validations of the tool (Twibell et al. , 2008; Chapman et al., 2013). No items were removed from the SC scale in this analysis (similar to Twibell et al., 2008 but not Chapman et al., 2013). The Cronbach's $\alpha$ for reliability is comparable across all three studies for the $\mathrm{SC}$ scale, but it is notable that the RB scale is more reliable in the original population on which it was developed than in either of subsequent two populations in which it was tested. Similarly, although the single factor identified by the factor analysis explained about half of the variation in responses to the SC scale (similar to the original Twibell et al. analysis), the comparable analysis for the RB scale explained considerably less of the variation observed (31\%) than in the previous analyses by Twibell et al. (53\%) or Chapman et al. (52\%).

These differences in scale performance may be explained in terms of differences in the populations studied. Twibell et al. (2008) developed the tools on experienced nurses in the United States with over two-thirds reporting that they had previously invited family members to attend resuscitation. Chapman et al. (2013) replicated the study on a sample of nurses and doctors who all worked in an emergency department in Australia, but only half of whom had 
invited family members to attend resuscitation. The current study took a quite different population, of student nurses in the United Kingdom, who had limited experience of nursing in general, very few of whom usually worked on critical care units or emergency departments, and the vast majority of whom had never invited family to attend resuscitation. It seems likely that most of the trainee nurses in this sample have experienced relatively few resuscitation attempts. Since the questions in the tools were not tailored to these relatively inexperienced student nurses, we anticipated that some of them were harder for the students to answer. Response rates to individual questions suggested that students found it easier to answer the questions about risks and benefits of family-witnessed resuscitation than their own confidence in dealing with it. Two exceptions to this in the RB scale were 'Nurses with whom I work are not supportive of family presence during resuscitation efforts', which only $86 \%$ respondents completed, and 'Family members on the unit where I work prefer to be present in the room during resuscitation efforts', which $87 \%$ of respondents answered. This probably reflects the lack of experience on the ward of the student nurses in our study, and is associated with a low factor loading for both these questions on the RB final scale. Other items in the RB scale that had a low factor loading (less than 0.35 ) were 'Family members will panic if they witness a resuscitation effort' and 'Family members will have difficulty adjusting to the long term emotional impact of watching a resuscitation effort'. The relatively low percentage of variance in the RB scale explained by the one-factor solution suggests that some of these questions were not so appropriate for our target audience as for more experienced nurses. Nevertheless, we set out to use the original tools, without changing the questions, as the first 
step in the development of tools tailored to student nurses. We have shown that the original tools developed by Twibell et al. (2008) for use with qualified nurses can be reliably used in this population to measure perceptions of the risks and benefits of family-witnessed resuscitation, and self-confidence in managing this situation. We have confirmed the internal consistency of these tools, but have not assessed the test-retest reliability of the scales over time, or content validity, which was assessed during the development of the original scale (Twibell et al., 2008).

The second objective was to report on perceptions of the risks and benefits of familywitnessed resuscitation, and levels of self-confidence in dealing with this situation, in the study population. Mean scores on the RB and SC scale were similar. The RB results are comparable with those reported by Twibell et al. (2008) but lower than those reported by Chapman et al. (2013). This may reflect a more positive attitude towards family-witnessed resuscitation in emergency departments compared with other settings. As we would expect with a student population, the scores on the SC scale were lower in this sample than in previously reported studies. A statistically significant relationship between the two scales was confirmed in this sample, though the correlation was weaker than in previous studies.

One of the limitations of our validation study was the smaller sample than that achieved in previous studies. There are many different rules of thumb regarding the optimal sample size for factor analyses, ranging from an absolute number of 100 to 500 (MacCallum, Widaman, 
Zhang \& Hong, 1999). Alternatively, the ratio of subjects to variables should reportedly be between 20:1 (Hair, Anderson, Tatham, and Black, 1995) and 2:1 (Kline, 1979). Our sample of 79 is suboptimal by all but the last of these indicators (we achieved a ratio of 1.8 subjects to items). Empirical analyses, however, suggest that smaller sample sizes (e.g. 50) and lower subject-to-variable ratios (e.g. 1.2) can yield clear results for factor analyses (MacCallum, Widaman, Zhang \& Hong, 1999). Nevertheless, future studies using these tools should aim for a larger sample size than that achieved here.

The high response rate in our study is a strength, and indicates that the sample studied is less likely to suffer from selection bias than previous studies. The number of statistically significant findings also suggests that the study was not under-powered; although it does not allow for detailed subgroup analyses, we did not set out to report on differences by demographic variables (such as age, gender or level of experience) since the population is homogeneous in these respects. Another significant limitation of our study is the high level of item nonresponse that arose as a consequence of delivering a questionnaire designed for qualified nurses to relatively inexperienced student nurses. As discussed above, this was done for the purposes of replication and validation, and respondents were told to leave questions blank if they felt that they did not apply to them as students. The item non-response, therefore, is not unexpected and serves to identify which questions may need to be modified in future developments of the tools for student nurses. Pairwise deletion was preferred over complete case analysis to maintain the sample size. Although the lack of imputation is a limitation of this 
approach, it has the advantage of ease of interpretability. Methods of multiple imputation (Donders et al., 2006) at the item-level rather than scale-level (Gottschall et al., 2012) should be considered in future work. For example, an analysis of data from the 12-Item Short Form Health Survey (Liu et al., 2005) has found that a simple model based on all available items was enhanced by including auxiliary variables, such as demographics which, though not collected in this study, could be useful in further studies.

Twibell et al. (2008) reported a linear association between the number of times nurses had invited family presence and scores on both the RB and SC scales. This finding was replicated by Chapman et al. (2013) who also found a linear association with years of experience in current role, age and educational level. So there is good evidence that the attributes measured by the RB and SC scales increase with experience and its correlates (e.g. age and educational qualifications). We hypothesize that the responses to these tools are likely to depend more specifically on exposure to resuscitation attempts. For example, those working in acute settings are more likely to be confident in their resuscitation skills than those in non-acute settings, and this was borne out by the risks, benefits and self-confidence reported by nurses in different settings (Twibell et al., 2008). Practitioners with less personal experience of resuscitation are likely to be influenced by the culture and attitudes of more experienced colleagues. Both role-modeling by individuals, and change at the institutional level (such as having a policy on family witnessed resuscitation) could be important in raising confidence around family-witnessed resuscitation. Educational opportunities to explore the topic are also 
likely to be important, although it has been noted that family presence at resuscitation is not addressed by most nursing curriculum (Norton et al., 2007).

Further work using larger samples could adapt the tools to be more appropriate to student nurses, by not asking questions about tasks that that they would not be expected to perform at this stage of their programme, for example. If such a tool performed significantly better for student nurses than the current tools validated here, then this would be important for any future studies looking at the effect of different educational interventions on students perceptions of family-witnessed resuscitation (such as that carried out by Kantrowitz-Gordon et al., 2013). Awareness of the risks and benefits of family-witnessed resuscitation should also be embedded in undergraduate curricula and continuing professional development opportunities (Salmond et al., 2014). A review of the current situation with regard to undergraduate nursing programs would be a good starting point in this endeavour.

\section{Conclusion}

The family-witnessed resuscitation RB and SC tools are valid and reliable for measuring student nurses' perceptions about family-witnessed resuscitation. There is a significant correlation between scores on these two scales. Student nurses self-reported professional competence to manage this family witnessed resuscitation is lower than that reported in studies of qualified healthcare professionals. 


\section{Keypoints}

1. We have validated the original family-witnessed resuscitation risk-benefit and self-

confidence scales (Twibell et al. (2008) for use with student nurses.

2. We observed a significant correlation between scores on the risks-benefit and selfconfidence scales, though it was not as strong as that reported in previous studies of more experienced practitioners.

3. These tools should be used to test interventions to increase student nurses perceptions of the benefits of family-witnessed resuscitation, and their self-confidence in dealing with familywitnessed resuscitation. 


\section{References}

Bandura A (1986) Social Foundations of Thought and Action A Social Cognitive Theory, Englewood Cliffs, NJ: Prentice Hall.

Bleda M-J and Tobias A (2000) Cronbach's $\alpha$ one-sided confidence interval. Stata Technical Bulletin, 56: 26-27.

Carroll D (2014) The effect of intensive care unit environments on nurse perceptions of family presence during resuscitation and invasive procedures. Dimensions of Critical Care Nursing 33(1): 34-9.

Chapman R, Watkins R, Bushby A and Combs S (2012) Family-witnessed resuscitation: perceptions of nurses and doctors working in an Australian Emergency Department. International Scholarly Research Network: Emergency Medicine 2012, Article ID 369423, 10 pages, 2012. doi:10.5402/2012/369423.

Chapman R, Watkins R, Bushby A and Combs S (2013) Assessing health professionals' perceptions of family presence during resuscitation: A replication study. International Emergency Nursing 21(1): 17-25.

Doyle CJ, Post H, Burney RE, Maino J, Keefe M, Rhee KJ (1987) Family participation during resuscitation: an option. Annals of Emergency Medicine 6(6):673-5.

Everitt, B.S. (2002) The Cambridge Dictionary of Statistics (2nd Edition), Cambridge: CUP. 
Fulbrook P, Latour J, Albarran J, Graaf de W, Lynch F, Devictor D and Norekval T (2007) The presence of family members during cardiopulmonary resuscitation: European Federation of Critical Care Nursing Associations, European Society of Paediatric and Neonatal Intensive Car and European Society of Cardiology Council on Cardiovascular Nursing and Allied Health professions- A position statement. European Journal of Cardiovascular Nursing 6(4): 255-258;

Gottschall AC, West SG and Enders CK (2012) A comparison of item-level and scale-level multiple imputation for questionnaire batteries. Multivariate Behavioral Research 47(1): 1-25.

Güneş Ü and Zaybak A (2009) A study of Turkish critical care nurses' perspectives regarding family-witnessed resuscitation. Journal of Clinical Nursing 18(20): 2907-2915.

Hair JFJ, Anderson RE, Tatham RL and Black WC (1995) Multivariate data analysis (4th ed.). Saddle River, NJ: Prentice Hall.

Hanson C and Strawser D (1992) Family presence during cardiopulmonary resuscitation: Foote Hospital emergency department's nine year perspective. Journal of Emergency Nursing 18(2): 104-106.

Hawthorne $G$ and Elliot P (2005) Imputing cross-sectional missing data: comparison of common techniques. Australian and New Zealand Journal of Psychiatry 39(7): 583-590.

Kantrowitz-Gordon I, Bennett D, Wise Stauffer D, Champ-Gibson E, Fitzgerald C and Corbett C (2013) Facilitated family presence at resuscitation: Effectiveness of a nursing student toolkit. Nursing Education Today 33(10): 1258-1263. 
Kline, P. (1979) Psychometrics and psychology. London: Acaderric Press.

Liu H, Hays RD, Adams JL, Chen WP, Tisnado D, Mangione CM, Damberg CL and Kahn KL (2005) Imputation of SF-12 health scores for respondents with partially missing data. Health Services Research 40(3): 905-21.

MacCallum RC, Widaman KF, Zhang S and Hong S (1999) Sample size in factor analysis. Psychological Methods, 4(1), 84-99.

MacLean S, Guzzetta CE, White C, Fontaine D, Eichhorn DJ, Meyers TA and Désy P (2003) Family presence during cardiopulmonary resuscitation and invasive procedures: practices of critical care and emergency nurses. Journal of Emergency Nursing 29(3): 208-221.

McLaughlin K, Melby V and Coates V (2013) Family centred care during resuscitation events. Emergency Nurse, 21(3):28-34.

McMahon-Parkes K, Moule P, Benger J and Albarran JW (2009) The views and preferences of resuscitated and non-resuscitated patients towards family-witnessed resuscitation: a qualitative study. International Journal of Nursing Studies 46(2): 220-229.

Meyers TA, Eichhorn DJ and Guzzetta CE (1998) Do families want to be present during CPR? A retrospective survey. Journal of Emergency Nursing 24(5): 400-5.

Meyers TA, Eichhorn DJ, Guzzetta CE, Clark AP, Klein JD, Taliaferro E and Calvin A (2000) Family Presence During Invasive Procedures and Resuscitation: The Experience of Family Members, Nurses, and Physicians. American Journal of Nursing 100(2): 32-43. 
Mortelmans LJ, Van Broeckhoven V, Van Boxstael S, De Cauwer HG, Verfaillie L, Van Hellemond PL, Van Colen S and Cas WM (2010) Patients' and relatives' view on witnessed resuscitation in the emergency department. European Journal of Emergency Medicine, 17(4): 203-7.

Norton CK, Dimon A, Knapp Richards R, Kelly S and Frey I (2007) The introduction of family presence evidence-based practice into a Baccalaureate Nursing curriculum. Critical Care Nursing Quarterly 30(4): 364-371.

Ponterotto, JG and Ruckdeschel DE (2007) An overview of coefficient $\alpha$ and a reliability matrix for estimating adequacy of internal consistency coefficients with psychological research measures. Perceptual and Motor Skills, 105(3): 997-1014.

Powers K (2014) Family presence during resuscitation of adults: the impact of an online learning module on critical care nurses' perception and self-confidence, PhD Thesis, School of Nursing, Division of Health Sciences, University of Nevada.

Rogers EM (1995) Diffusion of Innovations (4th edition), New York: Free Press.

Sacchetti A, Lichenstein R, Carraccio CA, Harris RH (1996) Family member presence during pediatric emergency department procedures. Pediatric Emergency Care 12(4): 268-271. Salmond SW, Paplanus LM and Avadhani A (2014) Using systematic reviews to guide decision making about family-witnessed resuscitation. Journal of PeriAnesthesia Nursing 29(6): 480 490. 
StataCorp (2011) Stata Statistical Software: Release 12. College Station, TX: StataCorp LP.

Tudor K, Berger J, Polivka BJ, Chlebowy R and Thomas B (2014) Nurses' perceptions of family presence during resuscitation. American Journal of Critical Care 23(6): e88-96.

Twibell RS, Siela D, Riwitis C, Wheatley J, Riegle T, Bousman D, Cable S, Caudill P, Harrigan S, Hollars R, Johnson D and Neal A (2008) Nurses' perceptions of their self-confidence and the risks and benefits of family presence during resuscitation. American Journal of Critical Care 17(2): 101-111.

Walker W (1999) Do relatives have the right to witness resuscitation? Journal of Clinical Nursing 8(6): 625-630.

Weslien M, Nilstum T, Lundqvist A and Fridlung B (2006) Narratives about Resuscitation Family Members Differ about Presence. European Journal of Cardiovascular Nursing 5(1): 6874. 
Table 1. Responses and factor analysis for the Risk-Benefit Scale Items

\begin{tabular}{|c|c|c|c|c|c|c|c|c|}
\hline $\begin{array}{l}\text { Original } \\
\text { item } \\
\text { number }\end{array}$ & Risk-benefit scale item & $\begin{array}{l}\text { Total } \\
\text { number of } \\
\text { responses } \\
\left(\text { response }^{1} \text { ) }\right. \\
\text { rate }^{1}\end{array}$ & $\begin{array}{l}\text { Strongly } \\
\text { disagree }\end{array}$ & Disagree & Neutral & Agree & $\begin{array}{l}\text { Strongly } \\
\text { agree }\end{array}$ & $\begin{array}{l}\text { Factor } \\
\text { loading }^{2}\end{array}$ \\
\hline 1 & $\begin{array}{l}\text { Family members should be given the } \\
\text { option to be present when a loved } \\
\text { one is being resuscitated. }\end{array}$ & $68(99 \%)$ & 2 & 4 & 18 & 26 & 18 & 0.40 \\
\hline 2 & $\begin{array}{l}\text { Family members will panic if they } \\
\text { witness a resuscitation effort. }\end{array}$ & 69 (100\%) & 0 & 2 & 39 & 23 & 5 & 0.31 \\
\hline 3 & $\begin{array}{l}\text { Family members will have difficulty } \\
\text { adjusting to the long term emotional } \\
\text { impact of watching a resuscitation } \\
\text { effort. }\end{array}$ & $69(100 \%)$ & 0 & 9 & 36 & 20 & 4 & 0.34 \\
\hline 4 & $\begin{array}{l}\text { The resuscitation team may develop } \\
\text { a close relationship with family } \\
\text { members who witness the efforts, as } \\
\text { compared with family members who } \\
\text { do not witness the efforts. }\end{array}$ & $69(100 \%)$ & 2 & 15 & 20 & 28 & 4 & $\mathrm{~N} / \mathrm{A}$ \\
\hline 5 & $\begin{array}{l}\text { I would be more anxious about doing } \\
\text { things right if family members were } \\
\text { present during a resuscitation effort. }\end{array}$ & $69(100 \%)$ & 3 & 6 & 8 & 42 & 10 & 0.37 \\
\hline 6 & $\begin{array}{l}\text { If my loved one were being } \\
\text { resuscitated, I would want to be } \\
\text { present in the room. }\end{array}$ & $69(100 \%)$ & 3 & 14 & 19 & 20 & 13 & 0.52 \\
\hline 7 & $\begin{array}{l}\text { Patients do not want family members } \\
\text { present during a resuscitation } \\
\text { attempt. }\end{array}$ & $68(99 \%)$ & 0 & 6 & 56 & 6 & 0 & $\mathrm{~N} / \mathrm{A}$ \\
\hline 8 & $\begin{array}{l}\text { The resuscitation team will try more } \\
\text { extensive interventions if family }\end{array}$ & $69(100 \%)$ & 8 & 23 & 24 & 13 & 1 & $\mathrm{~N} / \mathrm{A}$ \\
\hline
\end{tabular}




\begin{tabular}{|c|c|c|c|c|c|c|c|c|}
\hline & members are present. & & & & & & & \\
\hline 9 & $\begin{array}{l}\text { Family members who witness } \\
\text { unsuccessful resuscitation efforts will } \\
\text { have a better grieving process. }\end{array}$ & $69(100 \%)$ & 3 & 7 & 31 & 23 & 5 & 0.58 \\
\hline 10 & $\begin{array}{l}\text { If my loved one were being } \\
\text { resuscitated, I should be allowed to } \\
\text { be present because I am a nurse. }\end{array}$ & $69(100 \%)$ & 3 & 24 & 26 & 15 & 1 & N/A \\
\hline 11 & $\begin{array}{l}\text { Family members will become } \\
\text { disruptive if they witness } \\
\text { resuscitation efforts. }\end{array}$ & $69(100 \%)$ & 1 & 13 & 37 & 17 & 1 & 0.39 \\
\hline 12 & $\begin{array}{l}\text { Family members who witness a } \\
\text { resuscitation effort are more likely to } \\
\text { sue. }\end{array}$ & $65(94 \%)$ & 3 & 30 & 27 & 7 & 1 & 0.54 \\
\hline 13 & $\begin{array}{l}\text { The resuscitation team will not } \\
\text { function as well if family members } \\
\text { are present in the room. }\end{array}$ & 69 (100\%) & 2 & 31 & 22 & 12 & 2 & 0.52 \\
\hline 14 & $\begin{array}{l}\text { Nurses with whom I work are not } \\
\text { supportive of family presence during } \\
\text { resuscitation efforts. }\end{array}$ & $59(86 \%)$ & 1 & 16 & 32 & 9 & 1 & 0.21 \\
\hline 15 & $\begin{array}{l}\text { Family members on the unit where I } \\
\text { work prefer to be present in the } \\
\text { room during resuscitation efforts. }\end{array}$ & 60 (87\%) & 0 & 6 & 51 & 3 & 0 & 0.32 \\
\hline 16 & $\begin{array}{l}\text { The presence of family members } \\
\text { during resuscitation efforts is } \\
\text { beneficial to patients. }\end{array}$ & $66(96 \%)$ & 2 & 12 & 40 & 9 & 3 & 0.69 \\
\hline 17 & $\begin{array}{l}\text { The presence of family members } \\
\text { during resuscitation efforts is } \\
\text { beneficial to families. }\end{array}$ & 69 (100\%) & 2 & 7 & 31 & 25 & 4 & 0.82 \\
\hline 18 & $\begin{array}{l}\text { The presence of family members } \\
\text { during resuscitation efforts is } \\
\text { beneficial to nurses. }\end{array}$ & $67(97 \%)$ & 3 & 18 & 36 & 8 & 2 & 0.60 \\
\hline
\end{tabular}




\begin{tabular}{|c|c|c|c|c|c|c|c|c|}
\hline 19 & $\begin{array}{l}\text { The presence of family members } \\
\text { during resuscitation efforts is } \\
\text { beneficial to physicians. }\end{array}$ & 67 (97\%) & 3 & 16 & 42 & 5 & 1 & 0.54 \\
\hline 20 & $\begin{array}{l}\text { The presence of family members } \\
\text { during resuscitation efforts should be } \\
\text { a component of family-centred care. }\end{array}$ & 68 (99\%) & 0 & 6 & 24 & 31 & 7 & 0.61 \\
\hline 21 & $\begin{array}{l}\text { The presence of family members } \\
\text { during resuscitation efforts will have } \\
\text { a positive effect on patient ratings of } \\
\text { satisfaction with hospital care. }\end{array}$ & 67 (97\%) & 0 & 12 & 34 & 19 & 2 & 0.53 \\
\hline 22 & $\begin{array}{l}\text { The presence of family members } \\
\text { during resuscitation efforts will have } \\
\text { a positive effect on family ratings of } \\
\text { satisfaction with hospital care. }\end{array}$ & 69 (100\%) & 0 & 8 & 36 & 22 & 3 & 0.74 \\
\hline 23 & $\begin{array}{l}\text { The presence of family members } \\
\text { during resuscitation efforts will have } \\
\text { a positive effect on nurse ratings of } \\
\text { satisfaction in providing optimal } \\
\text { patient and family care. }\end{array}$ & 69 (100\%) & 0 & 8 & 37 & 20 & 4 & 0.80 \\
\hline 24 & $\begin{array}{l}\text { The presence of family members } \\
\text { during resuscitation efforts will have } \\
\text { a positive effect on physician ratings } \\
\text { of satisfaction in providing optimal } \\
\text { patient and family care. }\end{array}$ & 69 (100\%) & 0 & 7 & 40 & 18 & 4 & 0.77 \\
\hline 25 & $\begin{array}{l}\text { The presence of family members } \\
\text { during resuscitation efforts is a right } \\
\text { that all patients should have. }\end{array}$ & 59 (86\%) & 0 & 4 & 18 & 29 & 18 & 0.62 \\
\hline 26 & $\begin{array}{l}\text { The presence of family members } \\
\text { during resuscitation efforts is a right } \\
\text { that all family members should have. }\end{array}$ & 69 (100\%) & 1 & 8 & 24 & 27 & 9 & 0.39 \\
\hline
\end{tabular}


Table 2. Responses and factor analysis for the Self-Confidence Scale Items

\begin{tabular}{|l|l|l|l|l|l|l|l|l|}
\hline $\begin{array}{l}\text { Original } \\
\text { item } \\
\text { number }\end{array}$ & Self-Confidence scale item & $\begin{array}{l}\text { Total } \\
\text { number of } \\
\text { responses } \\
\text { (response } \\
\text { rate }{ }^{1} \text { ) }\end{array}$ & $\begin{array}{l}\text { Not at all } \\
\text { confident }\end{array}$ & $\begin{array}{l}\text { Not very } \\
\text { confident }\end{array}$ & $\begin{array}{l}\text { Somewhat } \\
\text { confident }\end{array}$ & $\begin{array}{l}\text { Quite } \\
\text { confident }\end{array}$ & $\begin{array}{l}\text { Very } \\
\text { confident }\end{array}$ & $\begin{array}{l}\text { Factor } \\
\text { loading }\end{array}$ \\
\hline 1 & $\begin{array}{l}\text { I could communicate about } \\
\text { the resuscitation effort to } \\
\text { family members who are } \\
\text { present. }\end{array}$ & $69(100 \%)$ & 1 & 22 & 27 & 15 & 4 & 0.50 \\
\hline 2 & $\begin{array}{l}\text { I could administer drug } \\
\text { therapies during } \\
\text { resuscitation efforts with } \\
\text { family members present. }\end{array}$ & $61(88 \%)$ & 5 & 21 & 21 & 12 & 2 & 0.54 \\
\hline 3 & $\begin{array}{l}\text { I could perform electrical } \\
\text { therapies during } \\
\text { resuscitation efforts with } \\
\text { family members present. }\end{array}$ & $62(90 \%)$ & 4 & 28 & 16 & 11 & 3 & 0.62 \\
\hline 4 & $\begin{array}{l}\text { I could deliver chest } \\
\text { compressions during } \\
\text { resuscitation efforts with } \\
\text { family members present. }\end{array}$ & $68(99 \%)$ & 1 & 7 & 22 & 26 & 12 & 0.60 \\
\hline 5 & $\begin{array}{l}\text { I could communicate } \\
\text { effectively with other health } \\
\text { team members during } \\
\text { resuscitation efforts with } \\
\text { family members present. }\end{array}$ & $69(100 \%)$ & 0 & 5 & 26 & 27 & 11 & 0.74 \\
\hline $\begin{array}{l}\text { I could maintain dignity of } \\
\text { the patient during } \\
\text { resuscitation efforts with }\end{array}$ & $69(100 \%)$ & 1 & 8 & 22 & 22 & 16 & 0.45 \\
\hline
\end{tabular}




\begin{tabular}{|c|c|c|c|c|c|c|c|c|}
\hline & family members present. & & & & & & & \\
\hline 7 & $\begin{array}{l}\text { I could identify family } \\
\text { members who display } \\
\text { appropriate coping behaviors } \\
\text { to be present during } \\
\text { resuscitation efforts. }\end{array}$ & $68(99 \%)$ & 4 & 15 & 25 & 17 & 7 & 0.61 \\
\hline 8 & $\begin{array}{l}\text { I could prepare family } \\
\text { members to enter the area } \\
\text { of resuscitation of their } \\
\text { family member. }\end{array}$ & $69(100 \%)$ & 2 & 17 & 22 & 21 & 7 & 0.81 \\
\hline 9 & $\begin{array}{l}\text { I could enlist support from } \\
\text { attending physicians for } \\
\text { family presence during } \\
\text { resuscitation efforts. }\end{array}$ & 67 (91\%) & 0 & 21 & 28 & 10 & 4 & 0.67 \\
\hline 10 & $\begin{array}{l}\text { I could escort family } \\
\text { members into the room } \\
\text { during resuscitation of their } \\
\text { family member. }\end{array}$ & 68 (99\%) & 1 & 7 & 28 & 24 & 8 & 0.72 \\
\hline 11 & $\begin{array}{l}\text { I could announce family } \\
\text { members' presence to } \\
\text { resuscitation team during } \\
\text { resuscitation efforts of their } \\
\text { family members. }\end{array}$ & 68 (99\%) & 0 & 9 & 25 & 25 & 9 & 0.78 \\
\hline 12 & $\begin{array}{l}\text { I could provide comfort } \\
\text { measures to family members } \\
\text { witnessing resuscitation } \\
\text { efforts of their family } \\
\text { member. }\end{array}$ & $68(99 \%)$ & 1 & 7 & 30 & 20 & 10 & 0.81 \\
\hline 13 & $\begin{array}{l}\text { I could identify spiritual and } \\
\text { emotional needs of family } \\
\text { members witnessing }\end{array}$ & $67(97 \%)$ & 2 & 13 & 31 & 15 & 6 & 0.83 \\
\hline
\end{tabular}




\begin{tabular}{|l|l|l|l|l|l|l|l|l|}
\hline & $\begin{array}{l}\text { resuscitation efforts of their } \\
\text { family member. }\end{array}$ & & & & & & & \\
\hline 14 & $\begin{array}{l}\text { I could encourage family } \\
\text { members to talk to their } \\
\text { family member during } \\
\text { resuscitation efforts. }\end{array}$ & $68(99 \%)$ & 1 & 25 & 23 & 14 & 5 & 0.80 \\
\hline 15 & $\begin{array}{l}\text { I could delegate tasks to } \\
\text { other nurses in order to } \\
\text { support family members } \\
\text { during resuscitation efforts } \\
\text { of their family member. }\end{array}$ & $67(97 \%)$ & 4 & 30 & 20 & 8 & 5 & 0.76 \\
\hline 16 & $\begin{array}{l}\text { I could debrief family after } \\
\text { resuscitation of their family } \\
\text { member. }\end{array}$ & $67(97 \%)$ & 6 & 30 & 14 & 14 & 3 & 0.78 \\
\hline 17 & $\begin{array}{l}\text { I could coordinate } \\
\text { bereavement follow-up with } \\
\text { family members after } \\
\text { resuscitation efforts of their } \\
\text { family members, if required. }\end{array}$ & $65(94 \%)$ & 4 & 19 & 28 & 10 & 4 & 0.76 \\
\hline $1 \mathrm{n}=69$ & & & & & & & & \\
\hline
\end{tabular}

$n=69$ 
